\title{
Crush behaviour of open cellular lattice structures manufactured using selective laser melting
}

\author{
M. Santorinaios, W. Brooks, C. J. Sutcliffe \& R. A. W. Mines \\ Department of Engineering, University of Liverpool, England, UK
}

\begin{abstract}
Open cellular lattice structures, made out of stainless steel, have been manufactured using the micro fabrication procedure of selective laser melting. A single geometry has been considered, namely vertical struts with cross bracing with a cell geometry of a cubic form. Blocks of this material, with dimensions of $25 \mathrm{~mm}$ cube, have been tested under compression and shear loading. Three cell sizes have been considered, namely $1.25,2.5$ and $5 \mathrm{~mm}$. Uniaxial compression and shear force versus displacement and failure characteristics of these materials are discussed, In this way, the micro mechanical characteristics of the material and manufacturing parameters are related to bulk properties.
\end{abstract}

Keywords: cellular, micro fabrication, selective laser melting, mechanical properties.

\section{Introduction}

Foams have been used for a number of years as core materials in sandwich construction for transport and general engineering systems. There is a wide variety of foam ranging from low density, high end technology applications, e.g. the Polymethacrylimide foam Rohacell 51WF for aerospace use [1], to high density/low end technology applications, e.g. the aluminium foam Alporas for civil engineering use [2]. The usual design parameters for sandwich construction focus on elastic response (specific stiffness and strength) [3], but more specialised behaviours include fatigue behaviour, crashworthiness and foreign object impact performance $[3,4]$. The mechanical behaviour of sandwich structures is dependent on the mechanical properties of the foam core and composite skin. As far as the foam core is concerned, the core can be subject to 
multi axial stresses and progressive failure in applications such as foreign object impact loading of sandwich panels [4].

The properties of foam cores are dependent on the parent material and the cell geometry [5]. Hence, for a given parent material, properties are adjusted by varying the foam density. This means that foams tend to be quasi isotropic, and that they tend to have a restricted range of properties. It should also be noted that low end foams have highly variable microstructure, which means that sophisticated modelling of mechanical behaviour is negated by the variation in bulk properties [4].

There is currently large interest in creating cellular structures with tailored cellular properties. These can be closed cell, open cell and framework type geometries. A number of manufacturing procedures are possible. This includes investment casting, deformation forming, brazing etc. [6]. Limitations of such techniques include the fineness of the structure, and the actual cell geometry. From the theoretical point of view, research is currently underway that addresses the analysis and optimisation of lattice structures in the context of core materials in sandwich construction [7].

Rapid prototyping techniques have been developed over the years to create complex geometries [8]. Selective laser melting is a new technique which allows the creation of metal structures with fine detail [9]. The technique that has been developed has the potential to create open cellular lattice structures with features with a resolution of 50 micro meters [10].

\section{Selective laser melting of open cellular lattice structures}

A schematic of the selective laser melting process is shown in Figure 1. The metallic powder is levelled off using a plate. A pre-programmed laser then traverses the powder surface, selectively melting areas of the surface. A new layer of powder is then deposited, and the process is repeated. In this way, a structure can be created in 50 micrometer layers.

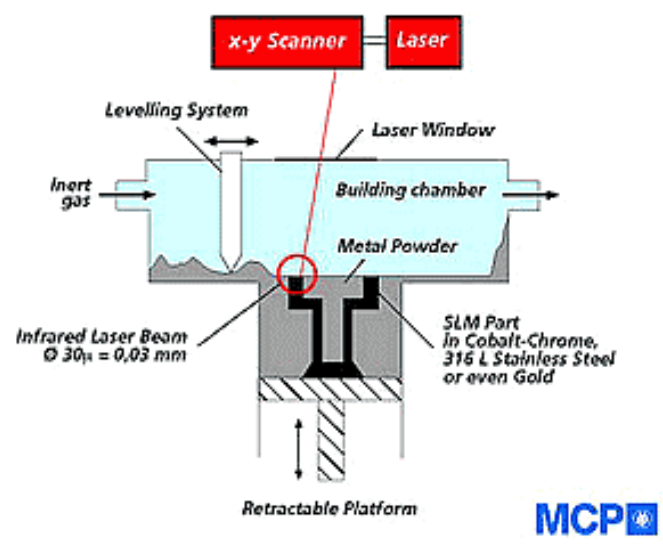

Figure 1: The Selective Laser Melting manufacturing process [9]. 
There are a large number of possible geometries possible, which gives large design freedom. The laser spot has a size of 50 micrometers, and any structural feature can be built to this resolution, as long as the newly solidified material can be built on top of the previous (solidified) layer. Figure 2 shows two cellular structures that can be created. The geometry is based on standard RP support geometries, but has features typical of general open cellular lattice structures. The structure consists of vertical members with diagonal cross members only, as currently, the process cannot build horizontal members. The powder used was Stainless steel 316L from Sandvik [11], and the powder grain size was between 10 and 38 micrometers. The finer the powder, the more expensive and dangerous (from combustion) it is.

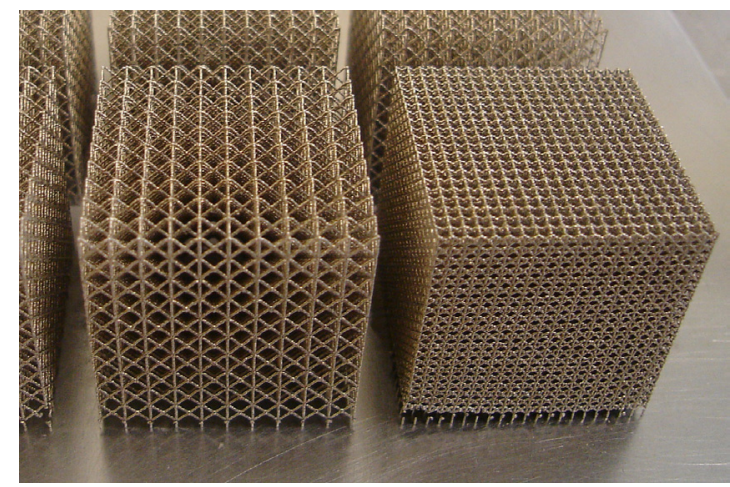

Figure 2: $\quad$ Builds for cell sizes of $2.5 \mathrm{~mm}$ and $1.25 \mathrm{~mm}$.

Figure 2 shows the cellular structures with $1.25 \mathrm{~mm}$ and $2.5 \mathrm{~mm}$ cell sizes. A $5 \mathrm{~mm}$ cell size was also considered, but this proved to be problematic to make. The struts tended to 'sag' during build, which meant that the final quality was unsatisfactory. In a single manufacture, six blocks were built on a steel plate base. The manufacture time for these six blocks was about 4 hours. The time of the process is dependent on the size and complexity of the cellular structure. There are about 500 laser passes to create the height of blocks. The blocks were cut from the steel bottom plate using a sharp knife, in an effort to reduce damage to cells. An important issue is the size and quality of the struts. This has been discussed in detail in Brocks et al. [10]. Two laser exposure times and two laser powers were used (see Table 1).

Table 1: $\quad$ Summary of builds (X number of specimen, 1 to 5).

\begin{tabular}{|l|l|l|l|l|}
\hline Build ID & $\begin{array}{l}\text { Cell size } \\
(\mathrm{mm})\end{array}$ & $\begin{array}{l}\text { Rel. Dens. } \\
(\%)\end{array}$ & $\begin{array}{l}\text { Laser Exp } \\
(\mathrm{ms})\end{array}$ & $\begin{array}{l}\text { Las. Pwr } \\
(\mathrm{A})\end{array}$ \\
\hline $1-\mathrm{X}-5$ & 5 & 0.8 & 2.5 & 2.25 \\
\hline $2 \mathrm{~L}-\mathrm{X}-2.5$ & 2.5 & 4.1 & 2.5 & 2.25 \\
\hline $2 \mathrm{H}-\mathrm{X}-2.5$ & 2.5 & 5.4 & 3.0 & 2.60 \\
\hline $3-\mathrm{X}-1.25$ & 1.25 & 12.5 & 3.0 & 2.60 \\
\hline
\end{tabular}


Figure 3 shows the detailed quality of the structure, in the form of an actual picture and in the form of a shadowgraph. The laser power was $2.6 \mathrm{~A}$ and the laser exposure time was 3 milliseconds. It can be seen that the struts are by no means cylindrical, and that there is the possibility of local imperfections. A feature of selective laser melting is molten material 'balling', which gives rise to beads being formed [12]. This shows the importance of careful control of manufacturing parameters. The strut diameter is on average 100 micrometers [10].
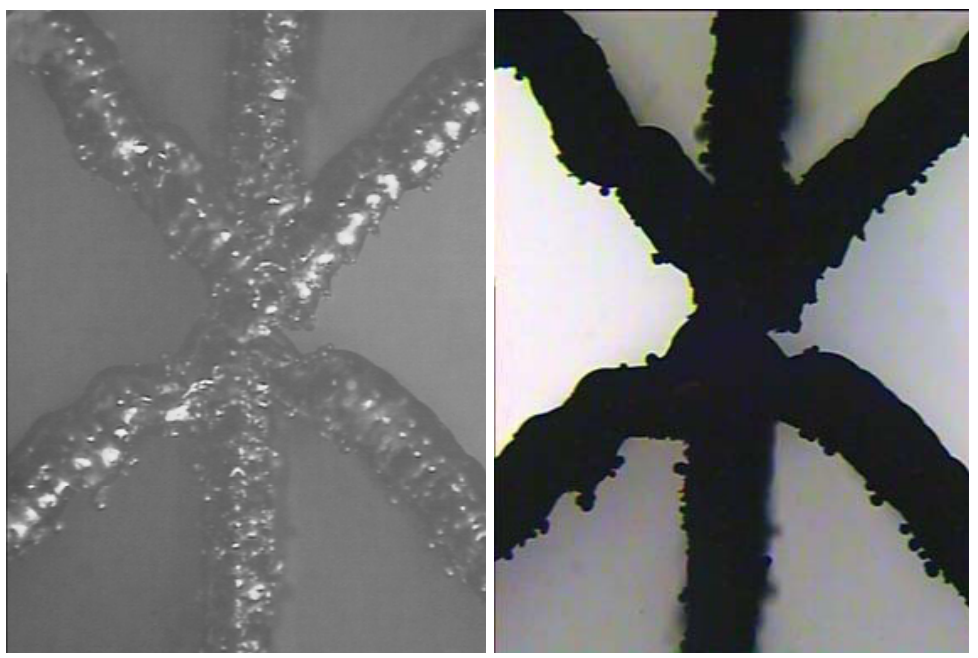

Figure 3: $\quad$ Photo and shadow graph of detail of $2.5 \mathrm{~mm}$ cell sized specimen.

\section{Compression tests and results}

$25 \mathrm{~mm}$ cube specimens were crushed along the cell vertical direction in a $50 \mathrm{kN}$ Instron testing machine at a displacement rate of $5 \mathrm{~mm} / \mathrm{min}$. The specimens were crushed between two steel platens and the stress and strain data was derived from load cell and crosshead data. Engineering stress and strain measures are used. Figure 4 gives stress $\mathrm{v}$ strain data for the three cell sizes, with stress being plotted on a log scale, for clarity. Figure 5 gives the failure mode for the $2.5 \mathrm{~mm}$ cube cell size case. It can be seen that the progressive crush is stable and that the major failure mode results from elastic-plastic buckling of the vertical struts. This gives rise to a 'shear band' forming in the complete specimen. Cells also fail near the base, which shows the need to improve the test to ensure failure in the bulk material. Zhou et al. [13] give an analysis of plastic buckling of struts, and show that the critical buckling load, $\mathrm{P}_{\mathrm{cr}}$ is given by:

$$
P_{c r}=\frac{12 C}{l}
$$


where $\mathrm{C}$ is a constant relating the plastic hinge couple of the strut, and 1 is the length of the strut. Hence the critical failure load should be inversely proportional to the strut length. Figure 6 checks out this hypothesis. Equation (1) is calibrated from the $2.5 \mathrm{~mm}$ cell data. The effect of the change of the number of vertical struts as a function of cell size is taken into account. The general trend is correct, showing that compression failure for this block and loading configuration is governed by strut length, strut cross section and parent material property.

Figure 7 gives the effect of manufacturing parameters. It compares the average crush stresses from the $2 \mathrm{H}$ tests with two $2 \mathrm{~L}$ tests. For details of specimens, see Table 1. It can be seen that manufacturing parameters are very important, and it should be noted that these need to be optimised before optimising the cell geometry.

It would be interesting to study the crush of the block in the lateral direction. It is proposed that, crush strength would be reduced, as there are no struts in that direction. Therefore this cellular material will be highly anisotropic.

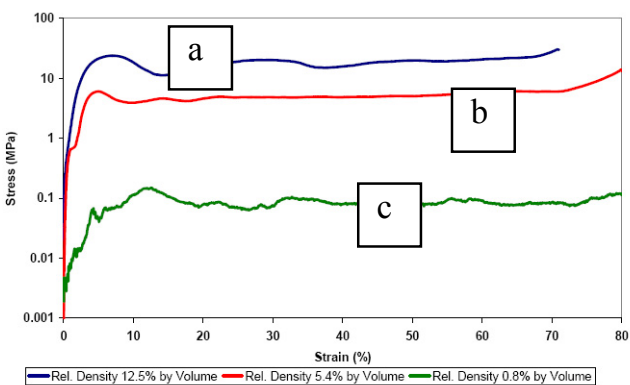

Figure 4: $\quad$ Stress v strain for three cell sizes (a. $1.25 \mathrm{~mm}$, b. $2.5 \mathrm{~mm}$, c. $5 \mathrm{~mm}$ ).

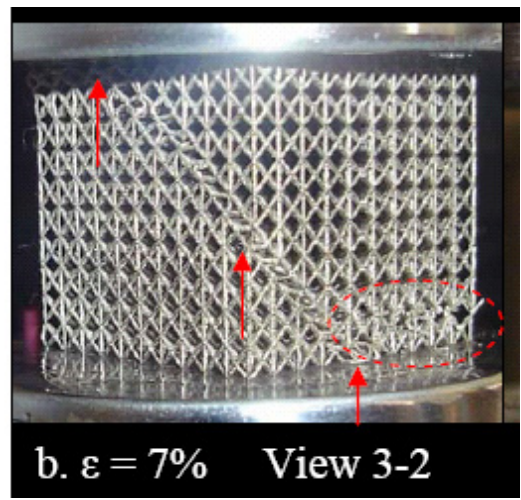

Figure 5: $\quad$ Failure of $2.5 \mathrm{~mm}$ cell size sample (H-2-2.5). 


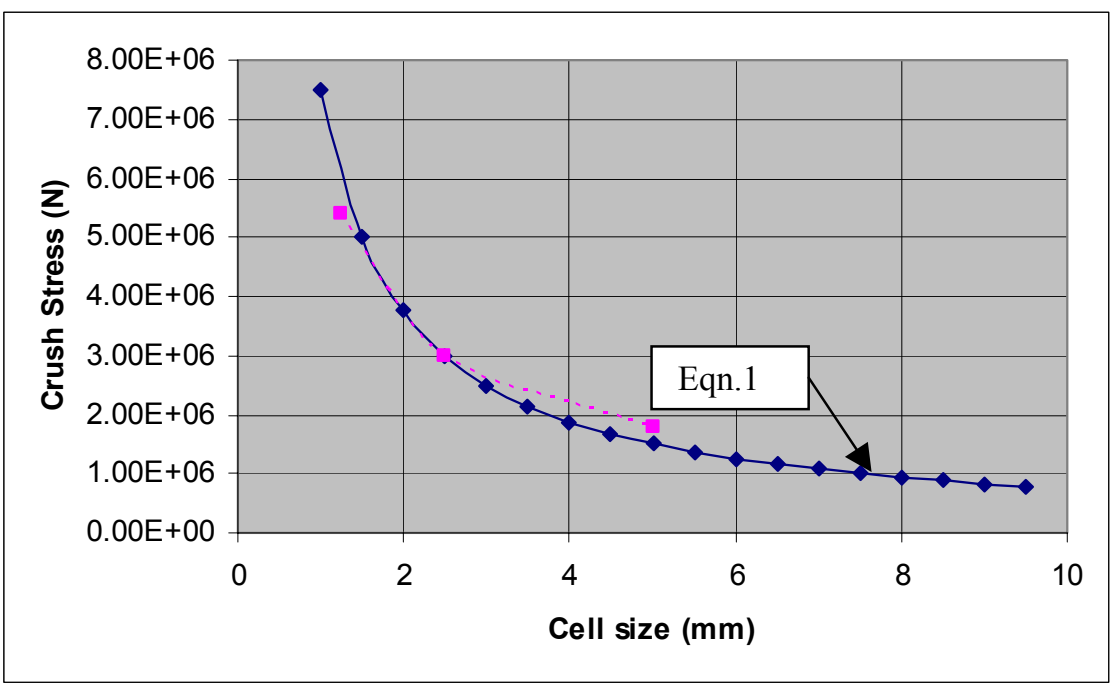

Figure 6: $\quad$ Predicted (from Equation (1)) and actual failure loads.

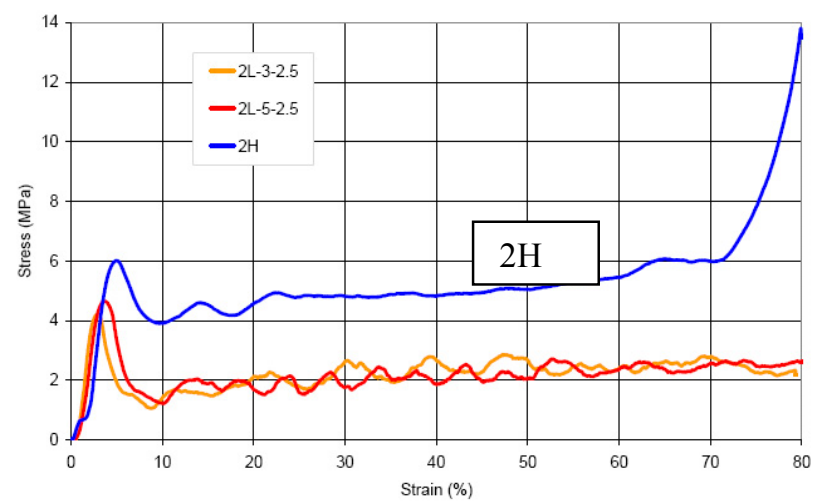

Figure 7: Comparison of the effect of manufacturing parameters on compression stress strain behaviour $(2.5 \mathrm{~mm}$ cell size $)$.

\section{Shear tests and results}

Foam cores in sandwich structures are subject to multi axial stresses, and so these have to be studied [4]. A tensile Arcan test [14] has been developed, in which combinations of tensile direct and shear stress can be applied to a block of foam. In this paper, shear only will be described. The $25 \mathrm{~mm}$ cube blocks are glued onto steel plates, which are then mounted in the Arcan Rig [14]. Figure 8 gives shear stress v strain data, and Figure 9 gives the failure modes for $1.25 \mathrm{~mm}$ and $2.5 \mathrm{~mm}$ cell sizes. 


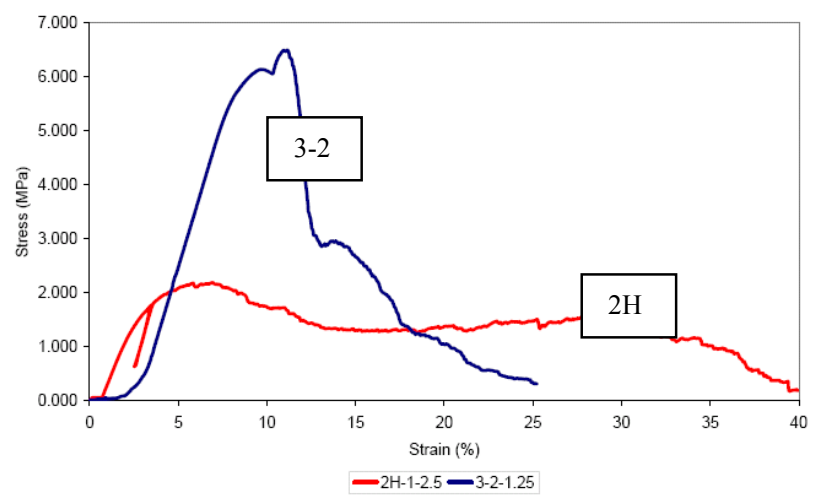

Figure 8: $\quad$ Stress strain data from Arcan shear tests.
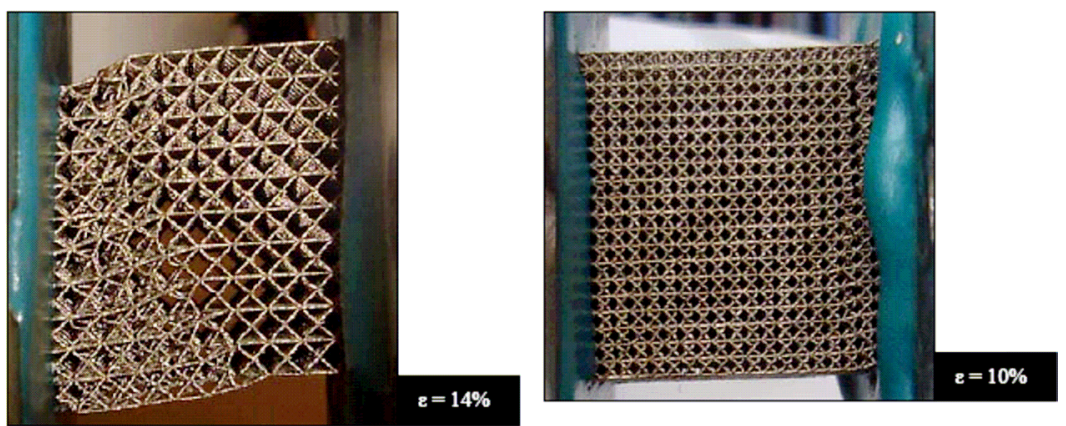

Figure 9: Comparison in failure modes for shear loading (2.5 and $1.5 \mathrm{~mm}$ cell sizes).

In both cases, failure initiates at the boundaries, showing the need to develop the test further, to ensure the initiation of failure for the bulk material. In the $2.5 \mathrm{~mm}$ cell size case, failure initiates by the buckling of the diagonal struts, whereas in the $1.25 \mathrm{~mm}$ cell size case, the whole block rotates, and failure is by tensile rupture of the vertical struts. The latter failure mode gives a more abrupt reduction in stress after failure. It would be interesting to conduct both biaxial and hydrostatic tests, as these are important for localised loadings in sandwich structures $[4,15]$. For the $2.5 \mathrm{~mm}$ cell size, the shear failure stress is about $6 \mathrm{MPa}$ which should be compared to the compression value of $10 \mathrm{MPa}$. This would indicate a failure surface typical of foams [15]. However, more unusual cellular structures may well give more unconventional failure surfaces.

\section{General discussion}

Figure 10 compares the bulk performance of the current cellular structure with other foams [16]. It can be seen that the structure performs well, and it should be 
noted that no attempt has been made to optimise the cell geometry. Therefore, it can be concluded that there is potential to markedly improve mechanical properties, over and above those of foams.

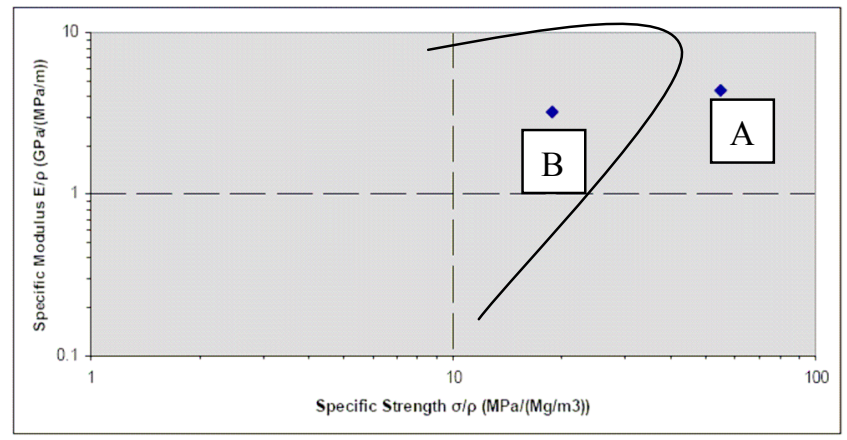

Figure 10: Comparison of current cellular structure with envelope for foams [16] (A - 1.25mm cell size, $\mathrm{B}-2.5 \mathrm{~mm}$ cell size $)$.

To summarise, there is scope to optimise the current cellular geometry. This needs to be addressed from a fundamental point of view - basically the manufacturing process can create any cellular structure with a resolution in structural features of about 50 micrometers.

The topology of the open cellular lattice structure can be optimised for elastic stiffness in bulk properties, and for non-linear (collapse) behaviour. A promising approach has been discussed by Bendsoe and Sigmund [17], in which a two dimensional solid is defined, and is populated by blocks ( 20 by 40 , for example). Boundary conditions are then applied to the geometry, and a linear finite element analysis is carried out. Blocks that are least structurally effective are then deleted, giving rise to the most efficient overall structure. Simple cases of beam bending have been analysed using MATLAB [17] and the approach can be extended to three dimensions. The optimisation approach has been applied to elastic stiffness problems [17], buckling problems [18] and crashworthiness problems [19].

\section{Concluding remarks}

A rapid prototyping manufacturing method is being developed to realise open cellular lattice structures that can be tailored for specific structural applications. A wide variety of structural geometries are possible. The synthesis of optimum structures (for a given application) is theoretically complex, and design tools need to be developed to maximise the potential of the selective laser melting manufacturing process. The analysis method of topology optimisation shows good potential for quantifying optimum performance.

A related issue concerns the simulation of the mechanical behaviour of these types of materials in the context of the actual structure. Periodic structures with 
small cell size give rise to a large number of structural features, which leads to unrealistic numerical models for full micro mechanical modelling. Also, in the case of foreign object impact loading, material behaviour is dynamic and highly non linear with damage occurring. There is a need to develop homogenised models, that characterise the effective behaviour of periodic structures [17].

\section{Acknowledgements}

The SLM machine has been funded by the EPSRC Grant number GR/598405/01 with contributions from MCP and Sandvik Osprey.

\section{References}

[1] Rohacell 51 WF Foam, Roehm Ltd., Bradbourne Drive, Tilbrook, Milton Keynes, Bucks, MK7 8AU, England, 1999.

[2] Alporas Data Sheet, Shinko Wire Company, Amagasaki, Japan, 2001.

[3] Zenkert, D.A., Introduction to Sandwich Construction, EMAS Publishers, 2000.

[4] McKown, S and Mines, R.A.W., Impact behaviour of metal foam cored sandwich beams, European Conference on Fracture 16, Alexandropoulos, Greece, Paper No. 254, July 2006.

[5] Gibson, L.J., and Ashby, M.F., Cellular Solids, Cambridge University Press, 1999.

[6] Wadley, H.N.G., Fleck N.A., Evans, A.G., Fabrication and structural performance of periodic cellular metal sandwich structures, Composites Science and Technology, 2004.

[7] Liu, J.S., Lu, T.J., Multi objective and multi loading optimisation of ultra lightweight truss materials, International Journal of Solids and Structures, Vol. 41, pp619-635, 2004.

[8] Chau, C.K., Leong, K.F., and Lim, C.S., Rapid Prototyping (2 ${ }^{\text {nd }}$ Edition), World Scientific, 2004.

[9] MCP Realiser II, MCP Tooling Technologies Ltd., Whitebridge Way, Whitebridge Ind. Park, Stone, Staffordshire, ST15 8LQ, England, 2005.

[10] Brooks, W.K., Tsopanos, S., Stamp, R., Sutcliffe, C.J., Cantwell, W.J., Fox. P., Todd, J., The production of open cellular lattice structures using selective laser melting, $6^{\text {th }}$ National Conference on Rapid Design, Prototyping, and Manufacturing, Buckinghamshire Chilterns University College, June 2005.

[11] Data sheet for microfine powders, 316L Austenitic stainless steel, Sandvik Osprey, Neath, Scotland, 2005.

[12] Kruth, J.P., Froyen L., Van Vaerenbergh, J., Mercelis, P., Rombouts, M., Lauwers, B., Selective melting of iron based powders, Journal of Materials Processing Technology, No. 149, pp616-622, 2004.

[13] Zhou, J., Shrotriya, P., Soboyejo, W.O., On the deformation of aluminium lattice block structures: from struts to structures, Mechanics of Materials, Vol. 36, pp723-737, 2004. 
[14] McKown, S., Mines, R.A.W., Measurement of material properties for metal foam cored polymer composite sandwich construction, Journal of Applied Mechanics and Materials, Vol. 1-2, pp211-216, 2004.

[15] Li, Q.M., Mines, R.A.W, and Birch, R.S., The crush behaviour of Rohacell 51WF structural foams, International Journal of Solids and Structures, Vol. 37, pp 6321-6341, 2000.

[16] Ashby, M.F., Materials selection in engineering design, Butterworth Heinemann, Oxford, 2005.

[17] Bendsoe, M.P. and Sigmund, O., Topology Optimization: Theory, Methods and Applications, Springer, Berlin, 2004.

[18] Neves, M.M., Sigmund, O., Bendsoe, M.P., Topology optimisation of periodic microstructures with buckling criteria, WCCM 5, Vienna, July 2002.

[19] Pedersen, C.B.W., Topology optimisation of energy absorbing frames, WCCM 5, Vienna, July 2002. 